\title{
Diffuse Retinoblastoma
}

National Cancer Institute

\section{Source}

National Cancer Institute. Diffuse Retinoblastoma. NCI Thesaurus. Code C66815.

A retinoblastoma characterized by the absence of a distinct retinal mass and the presence of malignant cells diffusely infiltrating the retina. It is often confused with uveitis and endophthalmitis, resulting in delayed diagnosis of the malignancy. 